\title{
The Role of Cardiovascular Disorders in the Pathogenesis of Acute Pneumonia
}

\author{
Igor Klepikov* \\ Pediatric Surgeon, USA
}

Submission: March 11, 2017; Published: March 27, 2017

*Corresponding author: Igor Klepikov, Pediatric Surgeon, 2116 27th St. NE Renton, WA 98056, USA, Tel: (425)264-5841;

Email: igor.klepikov@yahoo.com

\section{Introduction}

Pneumonia is a leading cause of hospitalization among children in the United States, with medical costs estimated at almost $\$ 1$ billion in 2009. Despite this large burden of disease, critical gaps remain in our knowledge about pneumonia in children [1]. "The rates of para pneumonic effusions have been increasing in the USA and Europe over recent years, and it is now encountered in approximately $40 \%$ of all patients with bacterial pneumonias" [2]. "Pediatric pleural empyema has increased substantially over the past 20 years and reasons for this rise remain not fully explained" [3]. The above quotes indicate low efficiency of the modern treatment of acute pneumonia (AP) and the absence of an explanation for this fact. Such a situation implies the search for new solutions to the problem.

To the present time, obtained much evidence of the important role of lung reflexes in the development and course of (AP). However, studies in this direction are mostly experimental and their clinical application is not even discussed [4,5]. I would like to offer the results of my research, which was published originally in Russian [6], and that may be interesting and informative for experts dealing with the problem of AP.

\section{Material and Methods}

The research was conducted in the clinic of pediatric surgery (Novokuznetsk, Russia) in 1982-1985 in patients with severe AP in the initial period of the disease. At that time children with the most aggressive forms of AP were selectively admitted to our department. These patients were non-surgical profile. The reason for the hospitalization was the fact that the surgical clinic was the only place in our area for intensive care. This group of patients differed high mortality and fast development of pleural complications. Unsatisfactory results of conventional treatment (massive doses of antibiotics, oxygen supply, intravenous infusion) forced us to find ways to solve the problem.
The following procedures have been used as a means of first aid in patients on admission.
A. Cervical vago sympathetic blockade (CVB) performed with $0.25 \%$ solution of novocaine on the side of inflammation. This type of blockade was allowed for clinical use and widespread in the Soviet Union, where the work was performed. These blockades were mainly recommended for carrying out differential diagnosis between abdominal syndrome of AP and acute appendicitis in children.

B. Cups therapy (Cup T) performed at the rate of 1 cup (50 cubic centimeters) to $4 \mathrm{~kg}$ body weight.

C. Cold wet wraps the body within a few minutes. This procedure is usually performed in patients with hyperthermia to the normalization of the temperature.

The effectiveness of procedures was evaluated by using comparative rheopulmonography (RPG). Record indicators was carried out prior to and immediately after the procedure. The electrodes for recording were applied on the side of the chest wall at the level of 3-4 ribs. Electrodes remained in the same place for the implementation of re-recording. Recording was carried out on the RPG-4 unit, "Elkar" (USSR). The age of patients these studies ranged from 3.5 to 14 years. Comparative RPG parameters were recorded in 22 children after CVB and in 14 children after the CupT. The effectiveness of cold wraps according to clinical signs was the most demonstrative, but we were not able to record the objective results.

Comparative RPG allowed to evaluate the respiratory rate $(\mathrm{RR})$, respiratory volume (RV), minute volume of ventilation (MV), heart rate (HR), systolic wave amplitude (SA), minute pulsatory blood flow (MBF), coefficient of ventilation-perfusion ratio $(\mathrm{Kv} / \mathrm{p})$. The results were subjected to statistical processing. 


\section{Results and Discussion}

Comparative RPG studies were objective evidence of the effectiveness of CVB and Cup T. Thus, indicators of RR and MV significantly decreased after the procedure, although RV remained unchanged. Performance SA, MBF has changed markedly, HR decreased to a lesser extent. In general, the received data reliably indicated a decrease of hyperventilation and improving perfusion. Baseline RPG indicated marked predominance indicators ventilation over the blood stream. Following treatment procedures, the ratio between these parameters $(\mathrm{Kv} / \mathrm{p})$ align. This point was accompanied by a significant improvement in the condition and well-being of patients.

The obtained results allowed us to evaluate the mechanisms of the development of the disease process in AP from new positions. Suddenly emerging center of inflammation causes reflectoric respiratory frequency excursions. Simultaneously reflectoric spasm of lesser circulation impedes the blood flow and causes delay and disruption of blood perfusion on the periphery. Violation of metabolic processes is the next link after the changes in the systemic circulation. Metabolism perversion serves as an additional incentive to compensatory increase in ventilation. Therefore, according to the original RPG, ventilation rates prevailed over the blood flow rates (Kv/p more than 1$)$.

The unique role of the lungs in the body is well known, including non-respiratory functions. Also it is well known that the reaction of everyone to certain stimulus has individual character. Therefore, the speeds of development of inflammation, the intensity of occurring disorders and the body's ability to adapt have a huge range of options. Reflex influence of inflammation in the lung on the small circle of blood circulation causes the inevitable restructuring of the systemic circulation.

The above-described changes in the peripheral circulation correspond to the picture "shock". Therefore homeostasis violations at AP, we were treated as "pulmonary shock". Treatment methods to eliminate those violations were named "anti-shock procedures".

The characteristics and course of action of therapeutic activities allow both inhibition of the inflammatory process and its stimulation. Therefore it is very important to have an understanding of the pathogenesis of the disease and the impact of medical procedures on its links. And should recognize the obvious fact that even more effective antibiotics will not allow to guarantee the prevention of the complications of AP. The key solution to this problem is hidden in the pathogenesis of the disease.

Performing SVB liquidates the reflectoric affect of inflammatory focus on the pulmonary vessels. This effect allows the body to eliminate violations of the central hemodynamics. The results of comparative RPG after CVB and after the Cup T had no significant difference. However, the mechanism of action of the Cup T seems to be different. Cups application extracts part of circulating blood and reduces venous return. This step unloads the vessels of the small circle and probably removes them from spasm. A similar mechanism will probably have cold wraps. This procedure also facilitates partial blood sequestration and pulmonary vascular unloading.

The presented above results have helped the author (along with other studies) to review the AP pathogenesis. Described first aid techniques entered in the obligatory treatment set of AP. The combinations of innovations have achieved impressive results of treatment of AP and declare the possibility of guaranteed prevention of its purulent and destructive complications. These results underline the fact that the AP is more circulatory than respiratory disaster.

This study was done by applying primitive equipment, but the results remain interesting today. Modern technology allows to conduct a similar study on a more detailed level and to get important information.

\section{References}

1. Jain S, Williams DJ, Arnold SR, Ampofo K, Bramley AM, et al. (2015) Community-Acquired Pneumonia Requiring Hospitalization among U.S. Children. N Engl J Med 372(9): 835-845.

2. Principi N, Esposito S (2011) "Management of severe communityacquired pneumonia of children in developing and developed countries". Thorax 66(9): 815-822.

3. Elemraid MA, Thomas MF, Blain AP, Rushton SP, Spencer DA, et al. (2015) Risk factors for the development of pleural empyema in children. Pediatric Pulmonology 50(7): 721-726.

4. Yang X, Zhao C, Gao Z, Su X (2014) A novel regulator of lung inflammation and immunity: pulmonary parasympathetic inflammatory reflex. QJM 10(10): 789-792.

5. Noble MI (2015) Abraham Guz memorial: Still unresolved hypotheses: Lung reflexes and perceptions of breathing. Respir Physiol Neurobiol 217: 46-53.

6. Klepikov I, Pogorelova L (1987) Pathogenesis and therapy of acute bronchogenic pneumonia. Pathological Physiology and Experimental Therapy 5: 41-44. 
This work is licensed under Creative Commons Attribution 4.0 License DOI: $10.19080 /$ JOCCT.2017.04.555628

\section{Your next submission with Juniper Publishers will reach you the below assets}

- Quality Editorial service

- Swift Peer Review

- Reprints availability

- E-prints Service

- Manuscript Podcast for convenient understanding

- Global attainment for your research

- Manuscript accessibility in different formats

( Pdf, E-pub, Full Text, Audio)

- Unceasing customer service

Track the below URL for one-step submission https://juniperpublishers.com/online-submission.php 